Article

\title{
Kinetics of the Volume Shrinkage of a Magnetite/Carbon Composite Pellet during Solid-State Carbothermic Reduction
}

\author{
Guang Wang *, Jingsong Wang and Qingguo Xue \\ State Key Laboratory of Advanced Metallurgy, University of Science and Technology Beijing, Beijing 100083, \\ China; wangjingsong@ustb.edu.cn (J.W.); xueqingguo@ustb.edu.cn (Q.X.) \\ * Correspondence: wangguang@ustb.edu.cn; Tel.: +86-010-82376018
}

Received: 21 October 2018; Accepted: 1 December 2018; Published: 11 December 2018

check for updates

\begin{abstract}
The volume shrinkage evolution of a magnetite iron ore/carbon composite pellet during solid-state isothermal reduction was investigated. For the shrinkage, the apparent activation energy and mechanism were obtained based on the experimental results. It was found that the volume shrinkage highly depended on the reduction temperature and on dwell time. The volume shrinkage of the pellet increased with the increasing reduction temperature, and the rate of increment was fast during the first $20 \mathrm{~min}$ of reduction. The shrinkage of the composite pellet was mainly due to the weight loss of carbon and oxygen, the sintering growth of gangue oxides and metallic iron particles, and the partial melting of the gangue phase at high temperature. The shrinkage apparent activation energy was different depending on the time range. During the first $20 \mathrm{~min}$, the shrinkage apparent activation energy was $51,313 \mathrm{~J} / \mathrm{mol}$. After the first $20 \mathrm{~min}$, the apparent activation energy for the volume shrinkage was only $19,697 \mathrm{~J} / \mathrm{mol}$. The change of the reduction rate-controlling step and the automatic sintering and reconstruction of the metallic iron particles and gangue oxides in the later reduction stage were the main reasons for the aforementioned time-dependent phenomena. The present work could provide a unique scientific index for the illustration of iron ore/carbon composite pellet behavior during solid-state carbothermic reduction.
\end{abstract}

Keywords: carbon composite pellet; direct reduction; shrinkage; kinetics; rotary hearth furnace

\section{Introduction}

Carbon composite pellets are made from a mixture of pulverized iron ore and carbonaceous material by briquetting or pelletizing at room temperature [1]. The iron oxide and the reducing agent contact closely with the large contact area, and the reduction rate is very fast during heating at temperatures from 1100 to $1300{ }^{\circ} \mathrm{C}$. It can be used for processing metallurgical dust [2], for producing direct reduced iron (DRI) [3], and for the utilization of complex iron ores [4-6]. If the reduction temperature is further increased above $1350^{\circ} \mathrm{C}$, the composite pellet will achieve melting separation and the slag-free pig iron nugget may be obtained, which is a high-grade burden of electric arc furnace (EAF) steelmaking $[7,8]$. Generally, the carbon composite pellet is charged on the smooth refractory hearth of the rotary hearth furnace (RHF), in no more than two pellet layers, and the pellet is heated by the thermal radiation of the furnace's gas and wall.

Most of the researchers in the field focus on the reduction rate and mechanism of the carbon composite pellet. However, one of the critical shortcomings of the RHF for iron ore reduction is its poor heat diffusion efficiency, when compared with the gas-solid countercurrent blast furnace. The heat from the furnace's gas and wall cannot efficiently be transported to the lower layers of a multilayer bed [9], which results in lower productivity. How to resolve the problem is also very meaningful for the 
further development of the technology. Fortunately, a few studies on the shrinkage of carbon composite pellets have been reported in the literature. Halder [9] found that if the volume of the top-layer pellets of a pellet bed shrinks by $30 \%$, then the external heat transfer to the second layer would increase by about six times. Therefore, the selection of easily shrinking iron ore and the development of an efficient method to strengthen the volume shrinkage of the pellet is of great significance for RHF reduction technology. Generally, the composite pellet shrinks considerably during the reduction due to the loss of carbon and oxygen from the system, sintering of the iron oxide, and the formation of a molten slag phase inside the pellet. Some researchers used empirical correlation to denote the pellet shrinkage when building the mathematical model of carbon composite pellet reduction $[10,11]$. However, each iron ore has its own unique shrinkage characteristics and it should be described in a more scientific method.

The shrinkage activation energy is a unique index for the illustration of the volume shrinkage of a carbon composite pellet during carbothermic reduction from the scientific viewpoint. However, few researchers have discussed and calculated the so-called volume shrinkage activation energy in their research work [9-11]. In the present paper, the reduction experiment of a carbon composite pellet with ordinary magnetite has been conducted at the laboratory scale, and then, for the shrinkage, the apparent activation energy was obtained by kinetics analysis. The present work can also provide a reference for studies on the reduction of other kinds of iron ores, as well as to help improve the development of highly efficient RHF reduction technology.

\section{Materials and Methods}

\subsection{Raw Materials}

The iron concentrate used in the present study was ordinary magnetite. The chemical composition of the ore sample and reducing agent are shown in Table 1 . The mineralogical analysis of the concentrate was investigated by X-ray diffraction (XRD) and showed that the main crystalline phases were magnetite $\left(\mathrm{Fe}_{3} \mathrm{O}_{4}\right)$ and a small amount of quartz $\left(\mathrm{SiO}_{2}\right)$, which is shown in Figure 1. The particle size of the iron ore concentrate was tested by a particle size analyzer and the results are shown in Figure 2, which illustrates that about $93 \%$ of the ore particles are smaller than $0.074 \mathrm{~mm}$. The reducing agent is a kind of anthracite with high fixed carbon content and low sulfur content. The fineness of the reducing agent is $100 \%$ passing through a $0.18-\mathrm{mm}$ mesh. The morphology of the magnetite concentrate powder is shown in Figure 3.

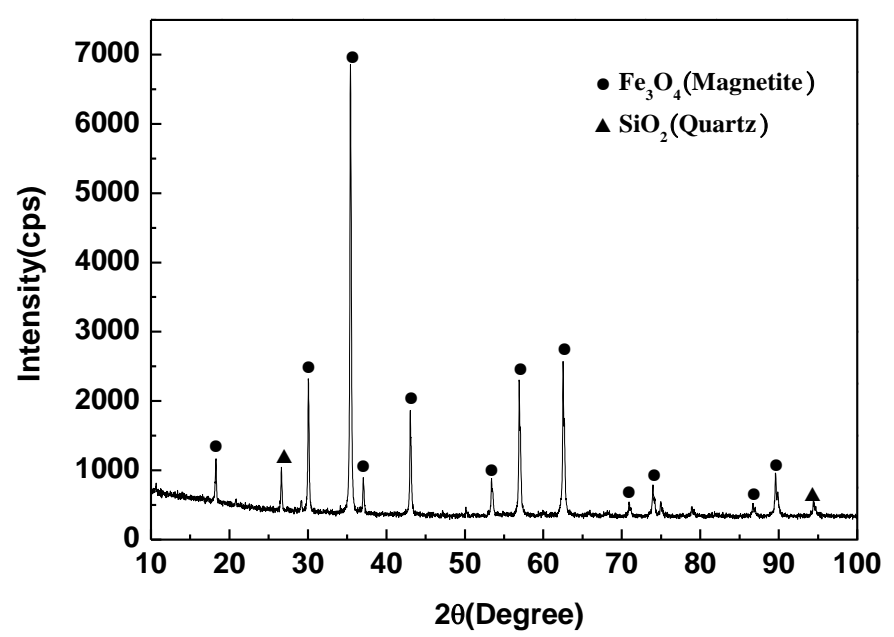

Figure 1. Results of the X-ray diffraction analysis of the iron concentrate. 
Table 1. Chemical composition of the raw materials (wt \%).

\begin{tabular}{ccccccccc}
\hline \multirow{2}{*}{ Iron Concentrate } & $\mathrm{TFe}$ & $\mathrm{FeO}$ & $\mathrm{SiO}_{2}$ & $\mathrm{Al}_{2} \mathrm{O}_{3}$ & $\mathrm{CaO}$ & $\mathrm{MgO}$ & $\mathrm{P}$ & $\mathrm{S}$ \\
\cline { 2 - 9 } & 64.6 & 29.3 & 7.21 & 0.18 & 0.17 & 0.20 & 0.01 & 0.21 \\
\hline \multirow{2}{*}{ Reducing Agent } & $\mathrm{FC}_{\mathrm{d}}$ & $\mathrm{V}_{\mathrm{d}}$ & $\mathrm{A}_{\mathrm{d}}$ & $\mathrm{S}$ & & & & \\
\cline { 2 - 7 } & 81.40 & 6.40 & 11.10 & 0.34 & & & & \\
\hline
\end{tabular}

Note: TFe is the total iron content, $\mathrm{FC}_{\mathrm{d}}$ stands for the fixed carbon (dry basis), $\mathrm{V}_{\mathrm{d}}$ is the volatile matter (dry basis), $A_{d}$ denotes ash (dry basis), and $S$ is the total sulfur.

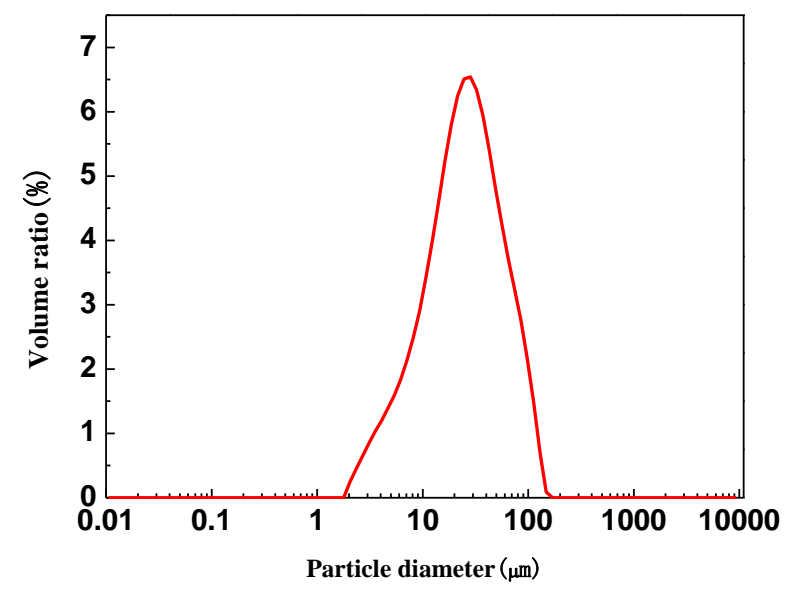

Figure 2. Particle size distribution of the iron concentrate.

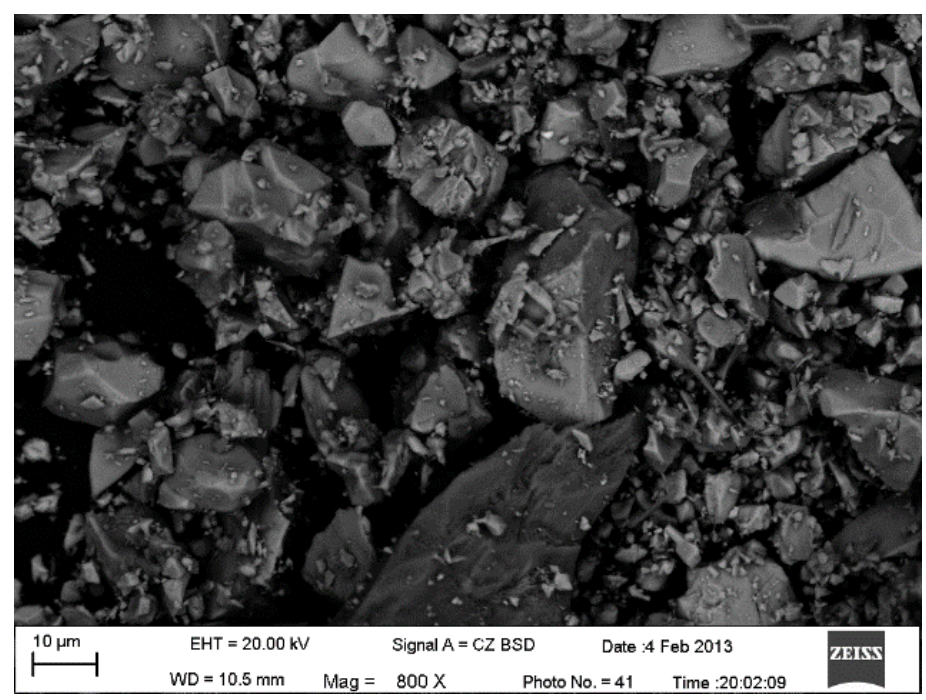

Figure 3. Particle morphology of the iron concentrate.

\subsection{Experimental Procedure}

In the preparation of the raw materials, the molar ratio between the fixed carbon in the reducing agent and the oxygen in the iron oxide in the iron concentrate was set as 1.0. Then, the iron concentrate and the reducing agent were fully mixed together to make the composition of the raw mixture uniform. The moisture of the raw material was set as $7 \%$. The pelletizing process was performed through a manual ball press under the pressure of $15 \mathrm{MPa}$. The pellet presented as column-like in shape and the size was $20 \mathrm{~mm}$ (diameter) $\times 10 \mathrm{~mm}$ (height). The green pellet was dried at $105{ }^{\circ} \mathrm{C}$ for $12 \mathrm{~h}$ before the reduction test. The reduction experiment was performed in a thermogravimetric system with a shaft $\mathrm{MoSi}_{2}$ resistance furnace, under the protection of high-purity $\mathrm{N}_{2}$ with a flow of $3 \mathrm{~L} / \mathrm{min}$. The dry composite pellet was put into a corundum crucible, and the crucible was suspended 
by $\mathrm{Fe}-\mathrm{Cr}-\mathrm{Al}-\mathrm{Mo}$ wire attached to an electronic balance and was heated at different temperatures. The heating temperatures were set at $1000{ }^{\circ} \mathrm{C}, 1050{ }^{\circ} \mathrm{C}, 1100^{\circ} \mathrm{C}, 1150{ }^{\circ} \mathrm{C}$, and $1200{ }^{\circ} \mathrm{C}$ in the reduction experiment. The full reduction time was $30 \mathrm{~min}$. Once the reduction finished, the reduced pellet was taken out of the furnace and was quickly cooled to room temperature under the protection of high-purity $\mathrm{N}_{2}$. The course of reaction can be expressed in terms of the "reaction fraction" (f), defined as in Equation (1):

$$
f=W_{\mathrm{t}} / W_{0}
$$

where $W_{\mathrm{t}}$ is the weight loss measured at a given time $t(\mathrm{~g})$ and $W_{0}$ is the maximum possible weight loss of the pellet $(\mathrm{g})$.

The content of total iron (TFe) and metallic iron (MFe) of the reduced pellet were obtained by chemical analysis, and the index of metallization degree $(\eta)$ was calculated by the following formula (2):

$$
\eta=\mathrm{MFe} / \mathrm{TFe} \times 100 \%
$$

The volume of the reduced pellet was measured by the wax immersion method [12], which can be calculated as follows:

$$
V=(P-S) / \rho_{0}-(P-W) / \rho
$$

where $V$ is the volume of the sample pellet $\left(\mathrm{cm}^{3}\right), P$ is the weight of the wax-coated specimen $(\mathrm{g}), W$ is the initial weight of the specimen using a balance $(\mathrm{g}), S$ is the weight of the wax-coated specimen when suspended in water $(\mathrm{g}), \rho$ is the density of wax $\left(\mathrm{g} / \mathrm{cm}^{3}\right)$, and $\rho_{0}$ is the density of water $\left(\mathrm{g} / \mathrm{cm}^{3}\right)$.

The mineral phases and microstructure of the reduced pellets were characterized by XRD and scanning electron microscope with energy-dispersive spectroscopy (SEM-EDS).

\section{Results}

\subsection{Variation of the Reaction Fraction and Mineral Phase Composition of the Pellet during Reduction}

The reaction fraction of the reduced composite pellet with time at different temperatures is shown in Figure 4. It can be clearly observed that the reaction fraction highly depends on the heating temperature and the reaction fraction increases with the increasing temperature. The line $\mathrm{A}-\mathrm{A}^{\prime}$ is the theoretical metallic iron emerging time (i.e., when the iron oxide in the pellet has been reduced into $\mathrm{FeO}$ ). The reaction fraction is $26.87 \%$ on this line. At the temperatures of $1000{ }^{\circ} \mathrm{C}$ and $1050{ }^{\circ} \mathrm{C}$, the reduction rate is low and the reaction does not reach a stable state at the time of $30 \mathrm{~min}$. When the temperature is greater than $1100^{\circ} \mathrm{C}$, the reduction reaction can reach a stable state at the time of $30 \mathrm{~min}$. It can also be seen that the reduction rate increases remarkably with the increasing of temperature when the temperature is lower than $1150{ }^{\circ} \mathrm{C}$. The metallic iron has appeared in all of the final reduced samples. The metallic iron appears earlier if the reduction temperature is higher. The fast reduction of the iron ore/carbon composite pellet will result in the formation of gaseous product and the loss of mass, which mainly leads to the consequent volume shrinkage.

The mineral phase compositions of the composite pellet reduced at different temperatures for $30 \mathrm{~min}$ were analyzed by XRD (Rigaku, Tokyo, Japan); the results are shown in Figure 5. The mineral phase components in the reduced pellets are relatively simple. For the $1000{ }^{\circ} \mathrm{C}$-reduced pellet, the main phases are metallic iron $(\mathrm{Fe})$, wustite $(\mathrm{FeO})$, and a small amount of silicon oxide $\left(\mathrm{SiO}_{2}\right)$; magnetite $\left(\mathrm{Fe}_{3} \mathrm{O}_{4}\right)$ has disappeared; and unreacted $\mathrm{SiO}_{2}$ does not exist in the form of quartz. In the XRD pattern of the $1050{ }^{\circ} \mathrm{C}$-reduced pellet, the peaks associated with the silicon oxide phase disappear, and the intensities of the wustite peaks decrease. In the pattern of the $1100{ }^{\circ} \mathrm{C}$-reduced pellet, the wustite peaks disappear, new peaks associated with fayalite $\left(\mathrm{Fe}_{2} \mathrm{SiO}_{4}\right)$ appear, and the intensities of the metallic iron peaks increase. In the pattern of the $1150{ }^{\circ} \mathrm{C}$-reduced pellet, the intensities of peaks associated with the fayalite and metallic iron phases begin to decrease a little. In the pattern of the $1200{ }^{\circ} \mathrm{C}$-reduced pellet, the intensities of the peaks associated with the fayalite become very weak and almost disappear, and metallic iron becomes the only major existing phase. 


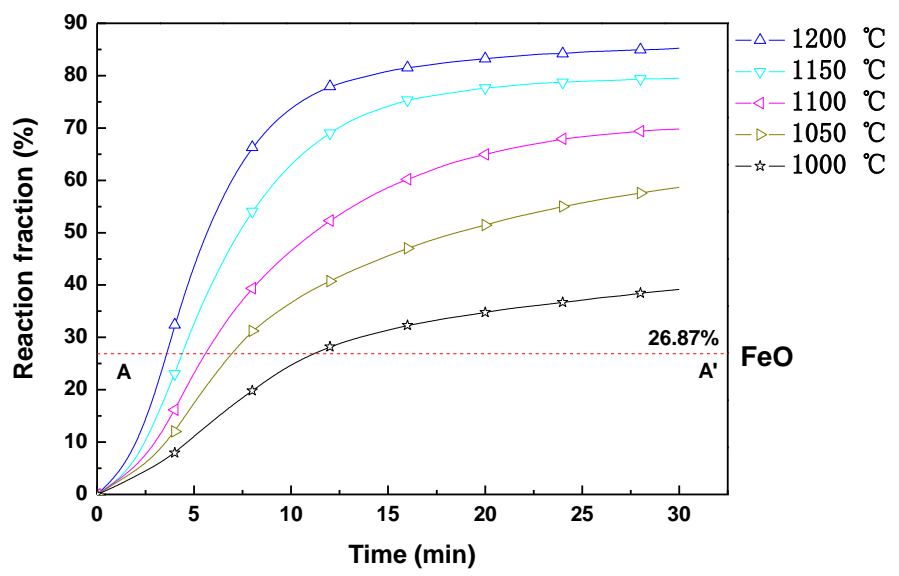

Figure 4. Results of the isothermal reduction experiment.

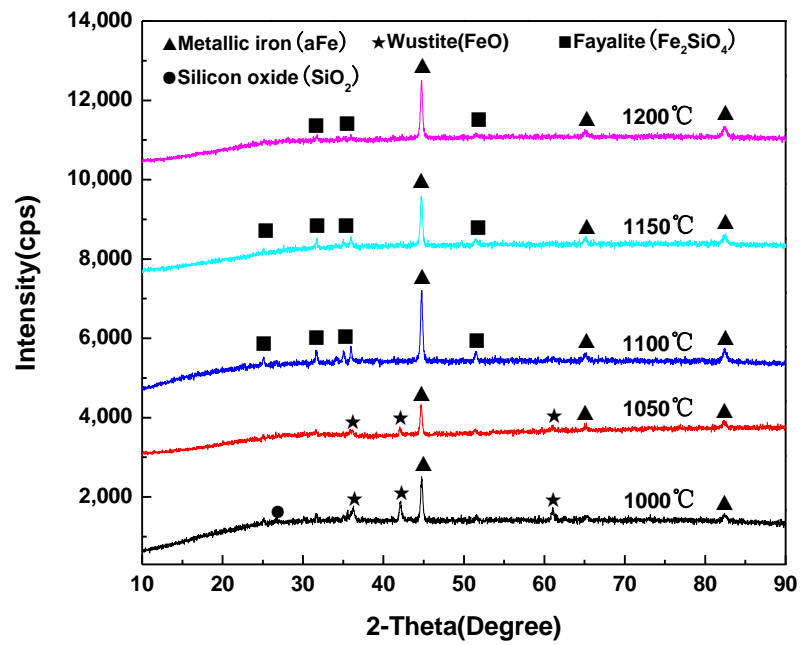

Figure 5. X-ray diffraction analysis of pellets reduced at different temperatures.

\subsection{Volume Shrinkage of Pellets during Reduction}

Figure 6 shows the variation in volume shrinkage of the composite pellets as a function of time at different temperatures. It can be seen that the volume shrinkage of the reduced pellet highly depends on the reduction temperature. Figure 7 shows the cross-sectional SEM images of composite pellets reduced at different temperatures for $30 \mathrm{~min}$. At the temperature of $1000{ }^{\circ} \mathrm{C}$, the shrinkage value is small because the reduction degree of the pellet is very low (39.2\%). The inner structure of the reduced pellet is still in the loose powdery state. The fine metallic iron particles have appeared around the edges of iron ore particles. It also can be seen that the edges of the quartz particles have partially reacted with $\mathrm{FeO}$, which forms from the $\mathrm{Fe}_{3} \mathrm{O}_{4}$ reduction, to form a new mineral phase. For the $1050{ }^{\circ} \mathrm{C}$-reduced pellet, the structure of the pellet becomes more denser and the particle size of metallic iron becomes obviously larger. More quartz particles have been reacted. Therefore, the pellet volume has shrunk a lot, from $12.2 \%$ to $25.6 \%$. For the $1100{ }^{\circ} \mathrm{C}$-reduced pellet, the structure of the pellet begins to change obviously, and the ore particles have sintered together and formed a lot of fayalite. The reaction fraction is approximately $69.8 \%$, and the metallic iron particles become larger. Thus, the volume shrinkage of the reduced pellet further increases to $35.8 \%$; a relatively large ratio. For the $1150{ }^{\circ} \mathrm{C}$ and $1200^{\circ} \mathrm{C}$-reduced pellets, the internal structures of the pellets become much denser. Although the peaks of fayalite are very weak in the XRD patterns of the $1150{ }^{\circ} \mathrm{C}$ - and $1200{ }^{\circ} \mathrm{C}$-reduced pellets, the fayalite still exists according to the SEM-EDS analysis. The SEM image of $1200{ }^{\circ} \mathrm{C}$-reduced pellet shows that the gangue phase is in a uniform state and might have melted to some extent, because the melting point of $\mathrm{Fe}_{2} \mathrm{SiO}_{4}$ is about $1205{ }^{\circ} \mathrm{C}$. The size of the metallic iron particles becomes much larger 
compared with that of the $1100{ }^{\circ} \mathrm{C}$-reduced pellet. The metallic iron particles begin to sinter together and form large-sized metallic crystal structures. Therefore, the reduced pellets continue to shrink.

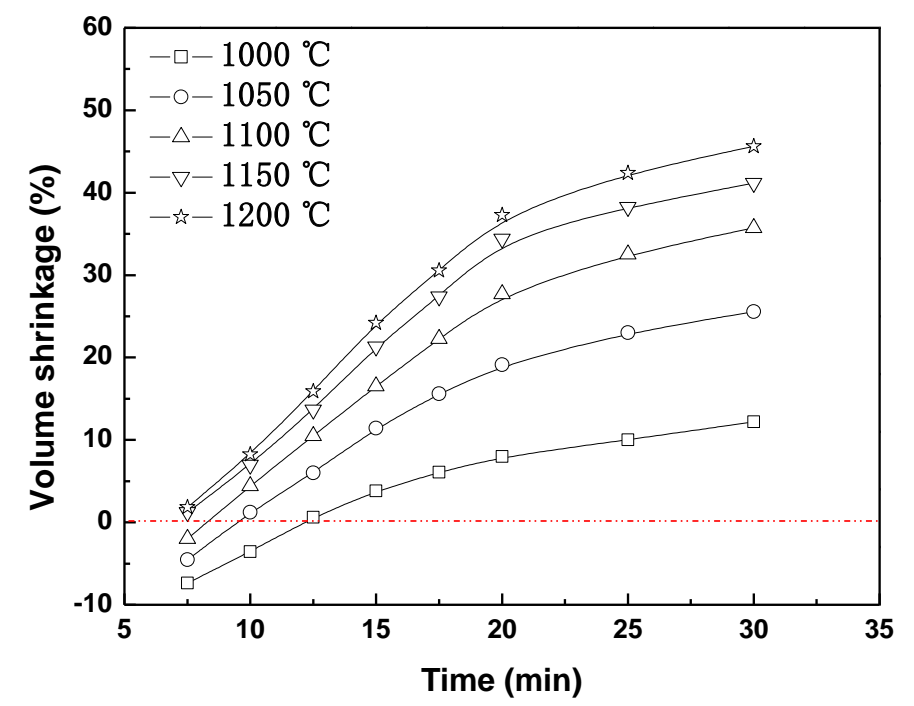

Figure 6. Volume shrinkage of the carbon composite pellets during reduction.

A summary of the variation of some properties, such as metallic iron particle size, fayalite fraction, and density, of the final reduced pellets at different temperatures is listed in Table 2, which can provide additional explanation for the reduction and shrinking process. The grain size of metallic iron gradually increases from $3.5 \mu \mathrm{m}$ to $16.5 \mu \mathrm{m}$ with the increasing temperature. Based on the SEM and $\mathrm{XRD}$ analysis, it can be concluded that the amount of fayalite is only small and the formation reaction of fayalite is just at the beginning stage owing to the relatively lower temperatures (i.e., $1000{ }^{\circ} \mathrm{C}$ and $1050^{\circ} \mathrm{C}$ ). The volume content of fayalite gradually decreases at the temperatures ranging from $1100{ }^{\circ} \mathrm{C}$ to $1200{ }^{\circ} \mathrm{C}$ due to the direct reduction of fayalite by solid carbon. The density of the final reduced pellets gradually increases from $2.36 \mathrm{~g} / \mathrm{cm}^{3}$ to $3.02 \mathrm{~g} / \mathrm{cm}^{3}$.

The volume shrinkage firstly increases rapidly before the 20-min timepoint, and then, the rate of change of shrinking is lower. At higher temperatures, the volume shrinkage rate increases because of a higher rate of carbon and oxygen loss from the pellet and a higher rate of sintering of the metallic iron particles and gangue oxides. It is also found that the shrinkage rate is negative at the beginning stage of the reduction process. This is because the iron oxide in the iron concentrate is magnetite $\left(\mathrm{Fe}_{3} \mathrm{O}_{4}\right)$ and the reduction of iron oxides follows in the sequence of magnetite $\left(\mathrm{Fe}_{3} \mathrm{O}_{4}\right) \rightarrow$ wustite $(\mathrm{FeO}) \rightarrow$ metallic iron (Fe). It is reported that there will be a 7 to $13 \%$ increase in volume during the transformation of $\mathrm{Fe}_{3} \mathrm{O}_{4}$ to $\mathrm{FeO}$ [13]. The pellets begin to shrink once the metallic iron particles appear in relatively large quantities. The highest volume shrinkage is about $45.6 \%$, when reduced at the temperature of $1200{ }^{\circ} \mathrm{C}$ under the present experimental conditions.

Figure 8 shows the variation of the volume shrinking rate of the composite pellets with time at different temperatures. The general trend is that the shrinking rate increases with the increasing reduction temperature. The obtained maximum shrinking rates are $1.60 \% / \mathrm{min}\left(1000^{\circ} \mathrm{C}\right), 2.30 \% / \mathrm{min}$ $\left(1050{ }^{\circ} \mathrm{C}\right), 2.55 \% / \mathrm{min}\left(1100{ }^{\circ} \mathrm{C}\right), 2.87 \% / \mathrm{min}\left(1150{ }^{\circ} \mathrm{C}\right)$, and $3.20 \% / \mathrm{min}\left(1200{ }^{\circ} \mathrm{C}\right)$, respectively. Thus, the higher the reduction temperature the pellets experience, the larger the volume shrinking rate becomes. The shapes of the shrinking rate curves indicate that the shrinking mechanism changes when the reduction temperature is greater than $1100{ }^{\circ} \mathrm{C}$. It can be concluded that the changing of the shrinking mechanism may be closely related to the reduction rate of iron oxide, the presence or absence of independent iron-containing minerals, and formation of the molten slag phase, among other factors. 

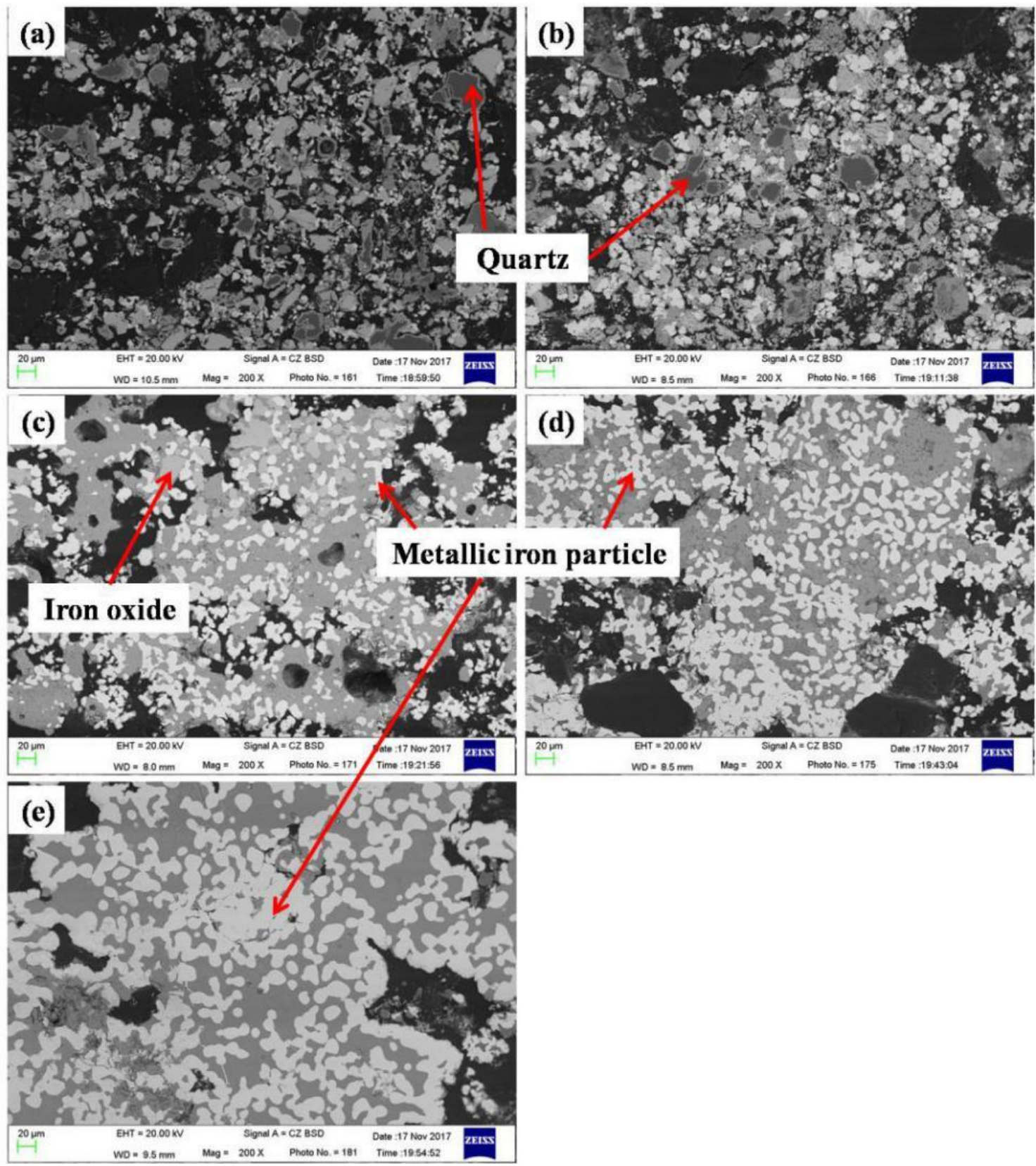

Figure 7. SEM images of the reduced pellets (at $30 \mathrm{~min}$ ): (a) $1000{ }^{\circ} \mathrm{C}$, (b) $1050{ }^{\circ} \mathrm{C}$, (c) $1100{ }^{\circ} \mathrm{C}$, (d) $1150{ }^{\circ} \mathrm{C}$, and (e) $1200^{\circ} \mathrm{C}$.

Table 2. Summary of some properties of the final reduced pellets.

\begin{tabular}{cccc}
\hline Temperature $\left({ }^{\circ} \mathbf{C}\right)$ & Metallic Iron Particle Size $(\mu \mathrm{m})$ & Fayalite Fraction $(\mathbf{v o l} \mathbf{\%})$ & Density $\left(\mathbf{g} / \mathbf{c m}^{\mathbf{3}}\right)$ \\
\hline 1000 & 3.5 & not detected/no data & 2.36 \\
1050 & 6.1 & not detected $/$ no data & 2.58 \\
1100 & 7.3 & 36.9 & 2.81 \\
1150 & 9.8 & 34.2 & 2.91 \\
1200 & 16.5 & 29.9 & 3.02 \\
\hline
\end{tabular}




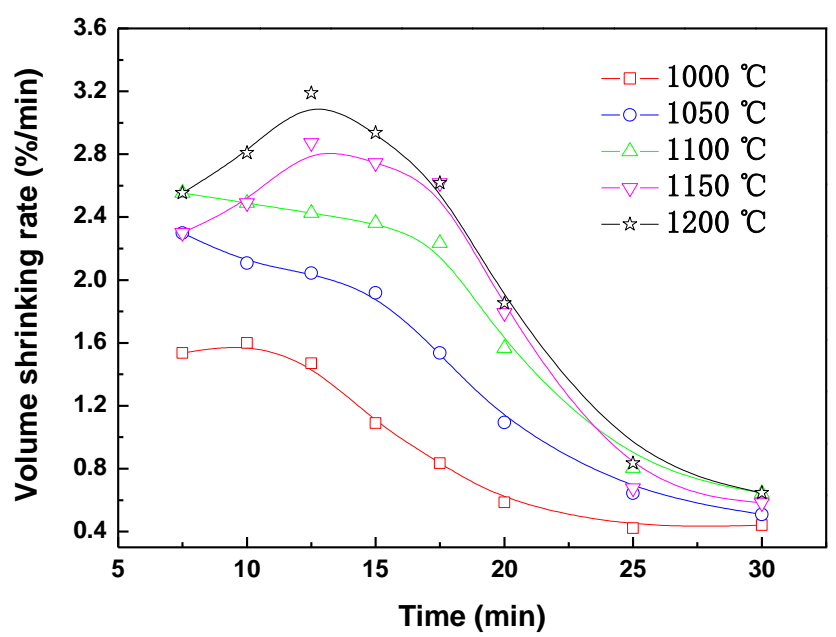

Figure 8. Volume shrinking rate of the carbon composite pellets during reduction.

\subsection{Shrinkage Kinetics Analysis}

The following Equation (4), which can be expressed as a function of time and temperature based on the work of McAdam [14], has been used to depict the volume shrinking behavior of iron ore/coal composite pellets in the present research.

$$
S h=k_{0} t^{2 / 5} \exp \left(-\frac{E}{R T}\right)=k t^{2 / 5}
$$

where $S h$ is the value of volume shrinkage $(\%), r_{0}$ is the initial pellet radius $(\mathrm{m}), k$ is the reaction rate constant, $k_{0}$ is the frequency factor, $t$ is the time $(\mathrm{min}), R$ is the ideal gas constant $(8.314 \mathrm{~J} /(\mathrm{mol} \cdot \mathrm{K})), E$ is the shrinkage apparent activation energy $(\mathrm{J} / \mathrm{mol})$, and $T$ is the temperature $(\mathrm{K})$.

Equations (5) and (6) can be obtained from Equation (4) and the Arrhenius equation. The value $\ln (k)$ can be calculated through the linear fitting between $\ln (S h)$ and $\ln (t)$ at certain temperatures. In the end, the value of $E$ can be obtained based on Equation (6).

$$
\begin{gathered}
S h=a(T)+k t^{2 / 5} \\
\ln (k)=\ln \left(k_{0}\right)-\frac{E}{R T}
\end{gathered}
$$

where $a(T)$ is the coefficient factor depending on the temperature and time range.

Equation (4) assumes that the pellet has a spherical shape; however, the pellet used in the present research has a columnar shape. It can be concluded that the volume shrinkage of the composite pellets during reduction is uniform and has little relation with the shape of the green pellet, because the chemical composition of the pelletizing raw material is uniform. On the other hand, the column-shaped pellet can be converted into a spherical pellet of the same volume, and then the equivalent radius value of the pellet can be obtained and implemented in the equation. Therefore, Equation (4) can also be utilized in the study of the shrinkage of nonspherical pellets.

The data of the $1000{ }^{\circ} \mathrm{C}$-reduced sample has not been taken into consideration due to the small shrinkage value. The linear fitting lines between $S h$ and $t^{2 / 5}$ in the range from $1050{ }^{\circ} \mathrm{C}$ to $1200{ }^{\circ} \mathrm{C}$ are listed in Figure 9. The reduction time is selected from $10 \mathrm{~min}$ to $30 \mathrm{~min}$. It can be seen that the linearity of the curves obviously changes at the time of $20 \mathrm{~min}$. Therefore, the curves are cut off at the time of $20 \mathrm{~min}$ and linear analyses are conducted separately. The linear correlation is perfect for each fitting. The calculated values of $k$ of the pellet volume shrinkage during reduction at the different temperatures are also listed in Figure 9. The obtained Arrhenius plot is shown in Figure 10. It can be seen that it is in better linearity when the pellet is reduced within $20 \mathrm{~min}$. The value of the apparent 
activation energy for the volume shrinkage during reduction is $51,313 \mathrm{~J} / \mathrm{mol}$ when the reduction time ranges from $10 \mathrm{~min}$ to $20 \mathrm{~min}$, and the apparent activation energy is 19,697 J/mol when the pellet is reduced for more than $20 \mathrm{~min}$. The equations describing the fractional shrinkage of the composite pellets at different reduction stages can be obtained according to the calculated data and are listed as follows. The $a(T)_{1}$ and $a(T)_{2}$ are coefficient factors depending on the specific temperature and time range, whose values are listed in Table 3.

$$
\begin{gathered}
S h_{1}=a(T)_{1}+2505.62 \times t^{2 / 5} \exp \left(-\frac{51313}{R T}\right) \quad\left(10-20 \mathrm{~min}, 1050{ }^{\circ} \mathrm{C} \text { to } 1200{ }^{\circ} \mathrm{C}\right) \\
S h_{2}=a(T)_{2}+68.98 \times t^{2 / 5} \exp \left(-\frac{19697}{R T}\right) \quad\left(>20 \mathrm{~min}, 1050{ }^{\circ} \mathrm{C} \text { to } 1200{ }^{\circ} \mathrm{C}\right)
\end{gathered}
$$

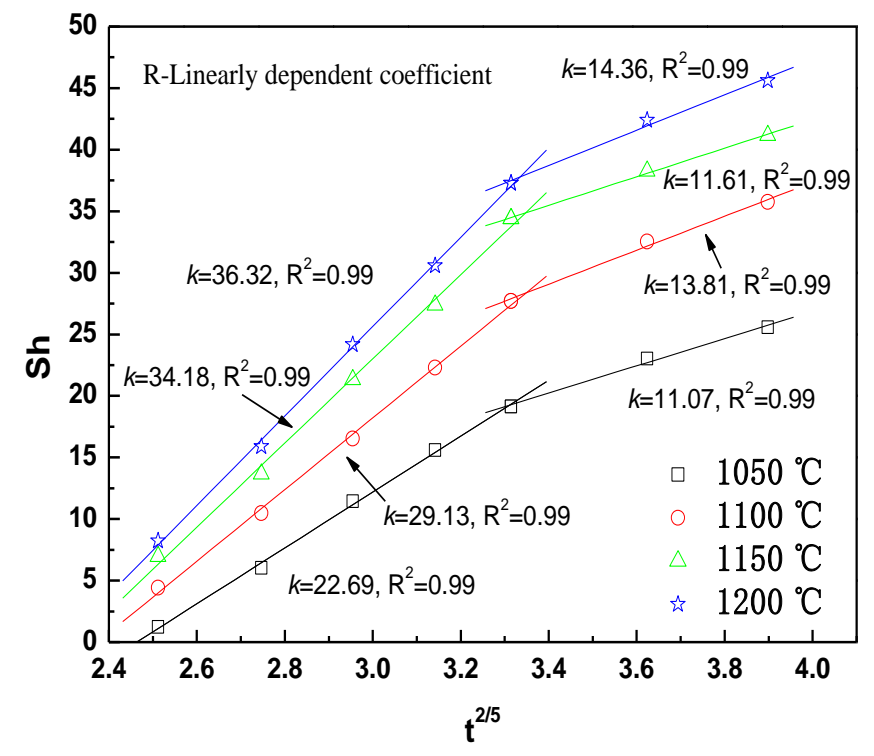

Figure 9. $\ln (S h)$ vs $\ln (t)$ curves. $S h$ : the value of volume shrinkage $(\%), t$ : time $(\min ), k$ : reaction rate constant.

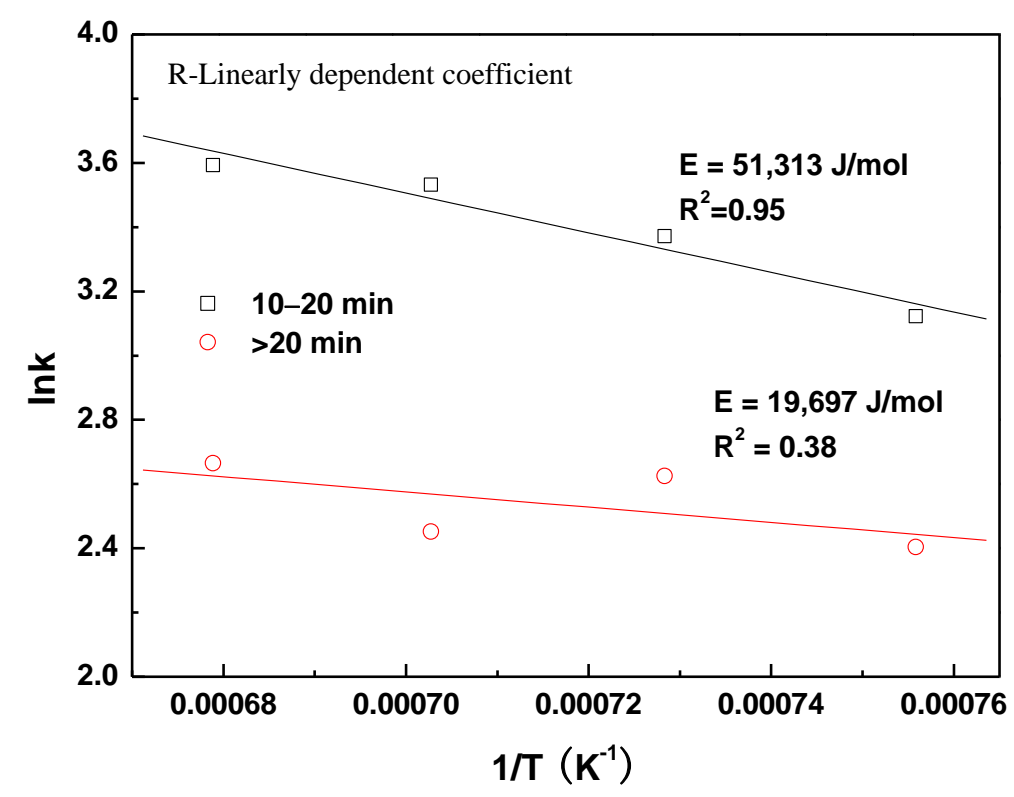

Figure 10. Arrhenius plot of the rate constant. E: the shrinkage apparent activation energy. 
Table 3. Coefficient factors $(a(T))$ for different temperatures and time ranges.

\begin{tabular}{ccc}
\hline Temperature $\left({ }^{\circ} \mathrm{C}\right)$ & $\mathbf{1 0 - 2 0} \mathbf{~} \min \left(\boldsymbol{a}(\boldsymbol{T})_{\mathbf{1}}\right)$ & $\mathbf{> 2 0} \mathbf{~} \min \left(\boldsymbol{a}(\boldsymbol{T})_{\mathbf{2}}\right)$ \\
\hline 1050 & -55.89 & -17.41 \\
1100 & -69.17 & -17.88 \\
1150 & -79.54 & -4.00 \\
1200 & -83.33 & -10.11 \\
\hline
\end{tabular}

\section{Discussion}

\subsection{Shrinkage Driving Forces}

Generally speaking, there are two main driving forces for the automatic growth and sintering together of metallic iron particles [15]. Firstly, the smaller particles contain relatively higher concentration of metallic iron atoms based on the Ostwald equation. Therefore, a concentration difference should exist for metallic iron between differently sized particles. Secondly, particles of relatively larger grain size tend to reduce the surface free energy because of the principle of minimum free energy. As a result of the two main theoretical reasons, Fe atoms will diffuse from tiny particles to bigger ones, and bigger particles will gradually sinter together and ultimately form large crystals. Therefore, small iron particles diminish and disappear, while larger particles reunite and grow as reduction progresses. The gangue oxide phase may also abide by the aforementioned two rules.

For the gangue oxide phase, at the initial reduction stage, the gangue minerals will sinter together and form new minerals simultaneously. As the magnetite contains quartz, the gangue minerals will partially melt, especially when the heating temperature approaches $1200{ }^{\circ} \mathrm{C}$. The formation of the molten slag phase will reduce the porosity of the pellet and make the pellet structure much denser after most of the iron oxide has been reduced into metallic iron.

\subsection{Time-Dependent Phenomena of Shrinkage Kinetics}

The above result shows that the apparent activation energy of shrinkage of the composite pellets changes obviously at the timepoint of 20 min during reduction. It can be concluded that the phenomena must be in close relation with the reduction rate and the evolution of the microstructure of the reduced pellets. The reduction and shrinkage behaviors of the composite pellets at $1200^{\circ} \mathrm{C}$ are used to make the discussion in this part.

Variation of the metallization degree of the reduced pellets with time at $1200{ }^{\circ} \mathrm{C}$ is shown in Figure 11. The metallization degree obviously increases during the time before $20 \mathrm{~min}$, and then increases slowly with the further increasing reduction time. Figure 12 illustrates the relationship between the volume shrinkage value and metallization degree of the pellets reduced at $1200{ }^{\circ} \mathrm{C}$. The correlation degree is perfect when using the quadratic equation of one unknown, which demonstrates that the volume shrinkage is highly dependent on the pellets' metallization degree. The reduction rate and rate-determining step must have changed since the 20 -min timepoint. Therefore, it can be concluded that the shrinkage mechanism should have also changed simultaneously with the change of the reduction rate-determining step, considering the close relationship between the metallization degree and volume shrinkage value. 


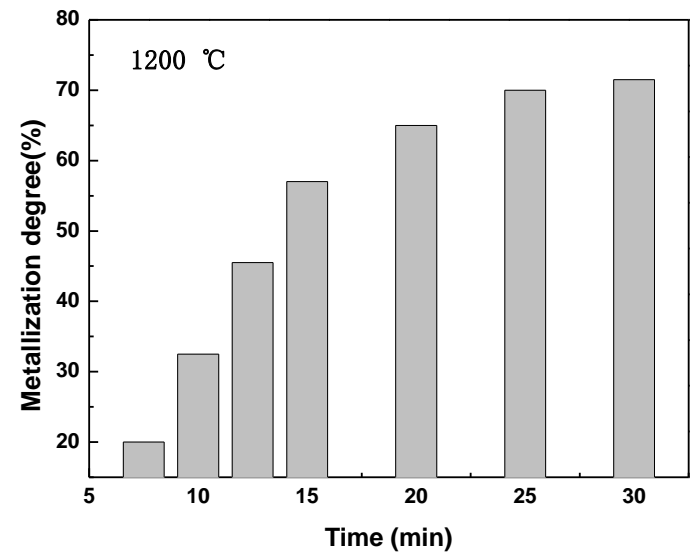

Figure 11. Metallization degree of the pellets reduced at $1200^{\circ} \mathrm{C}$.

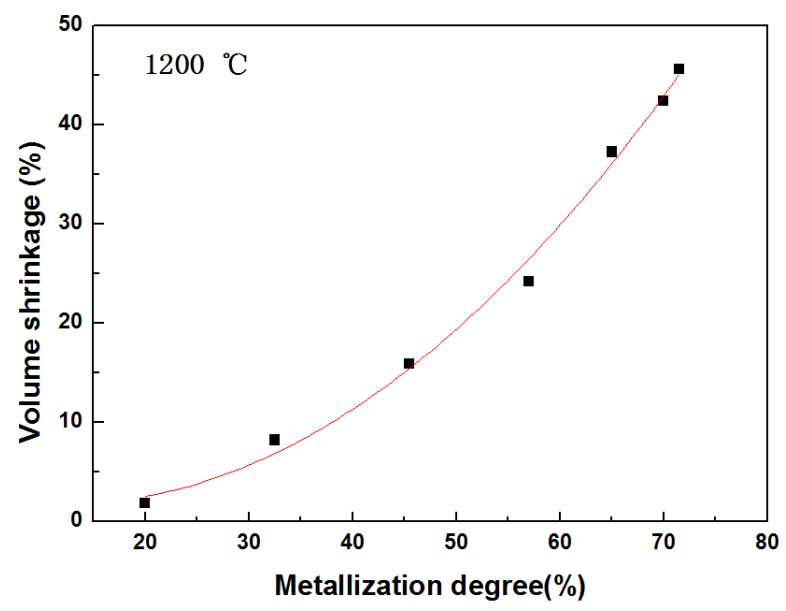

Figure 12. Correlation of volume shrinkage vs metallization degree of the pellets reduced at $1200{ }^{\circ} \mathrm{C}$.

Variation of the microstructure of the reduced pellets with time at $1200{ }^{\circ} \mathrm{C}$ is shown in Figure 13. With the reduction progressing, the internal microstructure also changes significantly from a loose powdery mixture to an increasingly dense sintered metallic iron-gangue phase. Once the composite pellet is heated, the reactions, such as iron oxide reduction, carbon gasification, metallic iron nucleation, iron grain growth, and new gangue mineral (i.e., fayalite) formation, will occur simultaneously and the volume of the pellet will shrink quickly during the time before $20 \mathrm{~min}$. At the timepoint of $20 \mathrm{~min}$, the internal microstructure of the reduced pellet has obviously changed compared with the 15 min-reduced pellet. The gangue mineral has developed into a lath shape from a granular shape, and the grain size of the metallic iron has become much larger. During the stage from $10 \mathrm{~min}$ to $20 \mathrm{~min}$ in the reduction process, the reactions are so complicated and difficult to occur; therefore, the shrinkage apparent activation energy is as high as $51,313 \mathrm{~J} / \mathrm{mol}$. With the reduction progressing to the later stage, the reduction of iron oxide has been almost completed, and the shrinkage of the reduced pellet mainly results from spontaneous sintering and reconstruction of the metallic iron particles and gangue oxides, and even partial melting of the gangue phase if the reduction temperature approaches the meting point of fayalite. The above reactions occur relatively easily and some occur spontaneously; therefore, the shrinkage apparent activation energy in the later reduction stage is only $19,697 \mathrm{~J} / \mathrm{mol}$. 

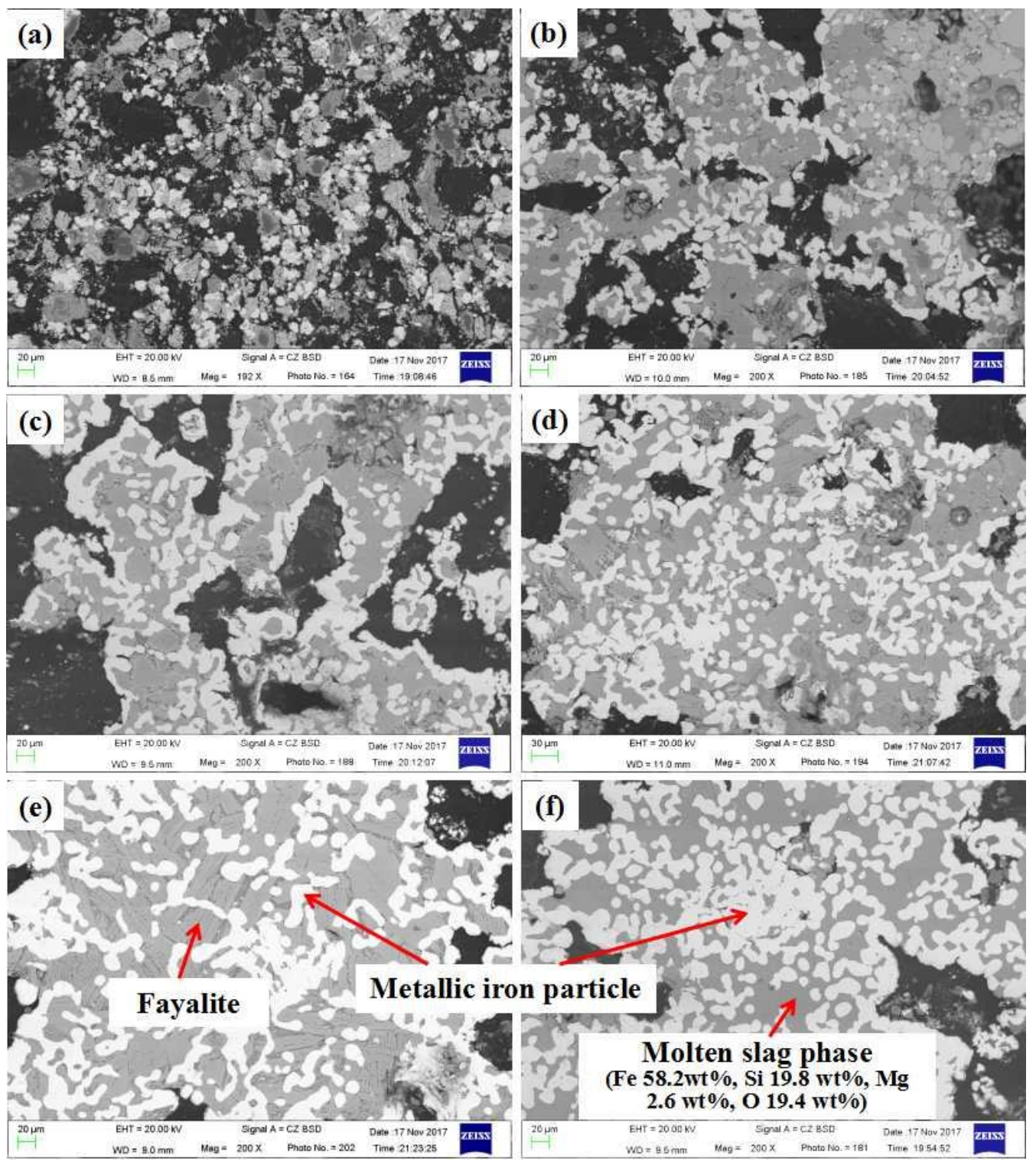

Figure 13. Microstructure of the pellets reduced at $1200^{\circ} \mathrm{C}$ : at (a) $7.5 \mathrm{~min},(\mathbf{b}) 10 \mathrm{~min},(\mathbf{c}) 12.5 \mathrm{~min},(\mathbf{d})$ $15 \mathrm{~min},(\mathbf{e}) 20 \mathrm{~min}$, and (f) $25 \mathrm{~min}$.

\subsection{Sensitivity Analysis for Shrinkage Kinetics Results}

In order to predict the response of the obtained kinetics equation, the calculation of the volume shrinkage with the variation of temperature and time is performed based on Equations (7) and (8), and the result is shown in Figure 14. It can be seen that the variation trend of the predicted values is similar to that of the measured ones. The root mean square error (RMSE) is simply computed and used to evaluate the accuracy of the kinetics equation. The RMSE calculation formula is given as follows [16]:

$$
R M S E=\sqrt{\frac{\sum_{i}^{N}\left(S h_{i}-S h_{i}^{\prime}\right)^{2}}{N}}
$$

where $S h_{i}$ is the measured value of volume shrinkage (\%) at different times under a given temperature, $S h_{i}{ }^{\prime}$ is the predicted value of volume shrinkage (\%) at different times under a given temperature, and $N$ is the number of pellets selected for volume measurement. 


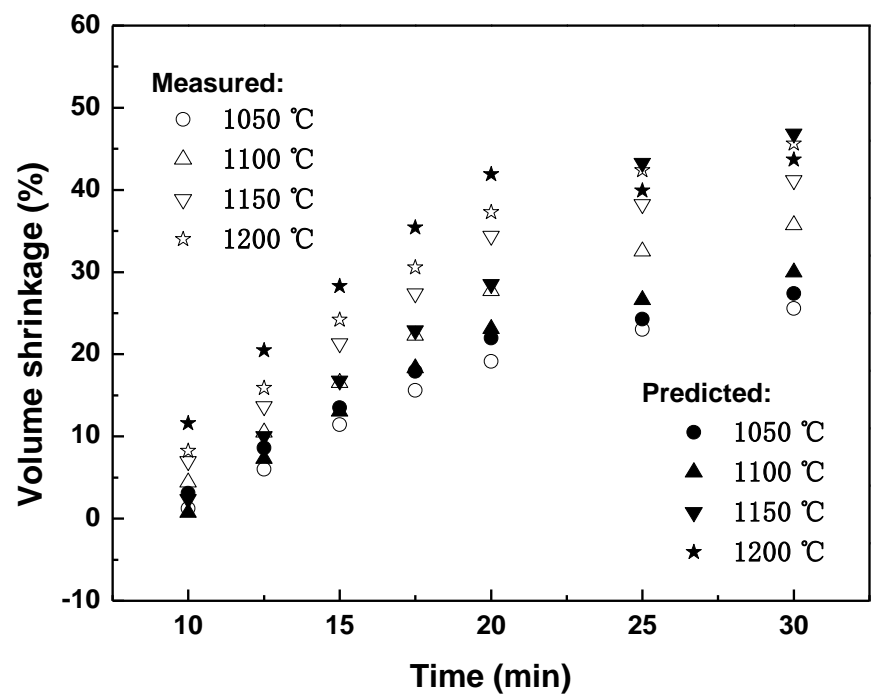

Figure 14. Comparison of measured and predicted volume shrinkage values.

The calculated RMSE values are listed in Table 4. The RMSE value at $1050{ }^{\circ} \mathrm{C}$ is the smallest, which indicates that the predicted volume shrinkage is comparatively more exact under the present condition. The RMSE values at $1100{ }^{\circ} \mathrm{C}$ and $1150{ }^{\circ} \mathrm{C}$ are relatively larger, which means they have worse accuracy.

Table 4. Root mean square error (RMSE) values.

\begin{tabular}{cccc}
\hline $\mathbf{1 0 5 0}{ }^{\circ} \mathrm{C}$ & $\mathbf{1 1 0 0}{ }^{\circ} \mathrm{C}$ & $\mathbf{1 1 5 0}{ }^{\circ} \mathrm{C}$ & $\mathbf{1 2 0 0}{ }^{\circ} \mathrm{C}$ \\
\hline 2.15 & 4.50 & 4.88 & 3.85 \\
\hline
\end{tabular}

\section{Conclusions}

(1) Volume shrinkage of the composite pellet increases with the increasing of reduction temperature, and the shrinkage rate is faster within the initial $20 \mathrm{~min}$. The values of shrinkage apparent activation energy are different at different time ranges. During pellet reduction before the 20-min timepoint, the shrinkage apparent activation energy is $51,313 \mathrm{~J} / \mathrm{mol}$ due to the complicated reactions. After the 20-min timepoint, the apparent activation energy of volume shrinkage is only $19,697 \mathrm{~J} / \mathrm{mol}$.

(2) The volume shrinkage of the composite pellet during reduction mainly results from the mass loss of carbon and oxygen and the sintering of the metallic iron particles and gangue oxides. With the increasing of reduction temperature and time, the formation of large metallic iron crystals and molten slag phase plays an important role in the further shrinkage of the reduced pellet in the final reduction stage.

Author Contributions: G.W. designed and performed the experiments and results analysis and acquired the funding. J.W. and Q.X. administrated the project, supervised the experiments, and reviewed the manuscript.

Funding: This research was funded by the National Natural Science Foundation of China, grant number 51804024, and the State Key Laboratory of Advanced Metallurgy of the University of Science and Technology Beijing, grant number 41618022.

Acknowledgments: The authors wish to acknowledge the contributions of associates and colleagues at the University of Science and Technology Beijing, China, and the financial support of the National Natural Science Foundation of China and the State Key Laboratory of Advanced Metallurgy of the University of Science and Technology Beijing.

Conflicts of Interest: The authors declare no conflict of interest. 


\section{References}

1. Yang, J.; Mori, T.; Kuwabara, M. Mechanism of carbothermic reduction of hematite in hematite-carbon composite pellets. ISIJ Int. 2007, 47, 1394-1400. [CrossRef]

2. Bauer, K.; Huette, D.; Lehmkuehler, H.; Schmauch, H. Recycling of iron and steelworks wastes using the Inmetco direct reduction process. Metall. Plant. Technol. 1990, 13, 74-87.

3. McClelland, J.M.; Metius, G.E. Recycling ferrous and nonferrous waste streams with FASTMET. JOM 2003, 55, 30-34. [CrossRef]

4. Wang, G.; Wang, J.S.; Ding, Y.G.; Ma, S.; Xue, Q.G. New separation method of boron and iron from ludwigite based on carbon bearing pellet reduction and melting technology. ISIJ Int. 2012, 52, 45-51. [CrossRef]

5. Ding, Y.G.; Wang, J.S.; Wang, G.; Xue, Q.G. Innovative methodology for separating of rare earth and iron from Bayan Obo complex iron ore. ISIJ Int. 2012, 52, 1772-1777. [CrossRef]

6. Chen, Y.; Hwang, T.; Marsh, M.; Williams, J.S. Mechanically activated carbothermic reduction of ilmenite. Metall. Mater. Trans. A 1997, 28, 1115-1121. [CrossRef]

7. Anameric, B.; Kawatra, S.K. Laboratory study related to the production and properties of pig iron nuggets. Miner. Metall. Proc. 2006, 23, 52-56. [CrossRef]

8. Kikuchi, S.; Ito, S.; Kobayashi, I.; Tsuge, O.; Tokuda, K. ITmk3 process. Kobelco. Techno. Rev. 2010, $29,77-84$.

9. Halder, S.; Fruehan, R.J. Reduction of iron-oxide-carbon composites: part III. shrinkage of composite pellets during reduction. Metall. Mater. Trans. B 2008, 39, 809-817. [CrossRef]

10. Donskoi, E.; McElwain, D.L.S. Mathematical modelling of non-isothermal reduction in highly swelling iron ore-coal char composite pellet. Ironmak. Steelmak. 2001, 28, 384. [CrossRef]

11. Donskoi, E.; McElwain, D.L.S. Estimation and modeling of parameters for direct reduction in iron ore/coal composites: Part I. Physical parameters. Metall. Mater. Trans. B 2003, 34, 93. [CrossRef]

12. Wang, G.; Xue, Q.G.; Wang, J.S. Volume shrinkage of ludwigite/coal composite pellet during isothermal and non-isothermal reduction. Thermochim. Acta 2015, 621, 90-98. [CrossRef]

13. Prakash, S. Reduction and sintering of fluxed iron ore pellets-a comprehensive review. J. South. Afr. Inst. Min. Metall. 1996, 96, 3-16.

14. McAdam, G.; O’Brien, D.; Marshall, T. Rapid reduction of New Zealand ironsand. Ironmak. Steelmak. 1977, 4, $1-9$.

15. Sun, Y.S.; Gao, P.; Han, Y.X.; Ren, D.Z. Reaction behavior of iron minerals and metallic iron particles growth in coal-based reduction of an oolitic iron ore. Ind. Eng. Chem. Res. 2013, 52, 2323-2329. [CrossRef]

16. Vu-Bac, N.; Lahmer, T.; Zhuang, X.; Nguyen-Thoi, T.; Rabczuk, T. A software framework for probabilistic sensitivity analysis for computationally expensive models. Adv. Eng. Softw. 2016, 100, 19-31. [CrossRef] 